\title{
High-Impact, Short-Term Study Abroad in Lyon, France: An Engineering Student's Perspective
}

\section{Alexander Kim, North Carolina State University}

Alex Kim is a Senior studying Chemical Engineering at North Carolina State University. He also serves as President of Musical Empowerment at NC State, a 501(c)(3) nonprofit.

\section{Dr. David F. Ollis, North Carolina State University}

David Ollis is Distinguished University Professor at North Carolina State University. A past chair of the Liberal Education Division of ASEE, he has been sending engineering students to the France IPL program for 15 years. He is co-editor, with Kay Neeley and Heinz Luegenbiehl, of Liberal Education in 21s Century Engineering.( Peter Lang, 2004) 


\section{High-Impact, Short-Term Immersion Study Abroad in Lyon, France: An engineering student perspective}

Introduction

A lab-and-language summer program in Lyon, France, was created in 2000 to provide international undergraduate STEM students with a French immersion experience. The program structure and its modifications over the years was described previously by the US faculty recruiter and the French faculty administrator. The present paper presents the perspective of a US student participant in this mixed lab-and-foreign language format.

Study abroad programs: Context

Engineering study abroad programs routinely suffer from multiple challenges, hence are characterized by relatively small enrollments and small numbers. Example challenges routinely include four items:

(1) Course formats overseas do not line up with US style/content

(2) Foreign language requirements may be severe

(3) US faculty often lead overseas effort, adding salary expense and suffering from lack of volunteers, and

(4) Student resistance from fear of financial cost as well as time delay for degree completion. 
We reported previously $(1,2)$ on a French engineering summer program which avoids all four of the challenges cited above. In particular, the French Institute Polytechnique de Lyon (IPL) offers five week summer programs with the following features:

(1) Five week summer program in June-July avoids conflict with US academic calendars

(2) French language courses are offered at beginning, intermediate, and advanced levels, so any interested students qualify

(3) All language and laboratory instruction is provided by French personnel, so no US faculty presence and salary are required, and

(4) The net summer cost is basically the price of the US/France air ticket. The tuition is free, and academic credit is transferable ( 7 units at NCSU). Housing and local transportation come at cost approximately equal to the same course load in a US summer. An additional advantage of the French program is that IPL is a combination of four engineering schools, CPE-Lyon, ECAM-Lyon, ISARA-Lyon, and ITECH-Lyon, and thus offers summer programs in a broad range of engineering subjects, as the following specializations of each IPL school indicate:

CPE-Lyon: Chemistry, chemical engineering, physics, and electronics

ECAM-Lyon: Energy and sustainability

ISARA-Lyon: Agriculture, food and environmental science

ITECH-Lyon: Materials, chemistry, cosmetics, and leather

We have published two descriptions of this French IPL program, initiated in 2000. The first version (1) described the initial non-credit, three week summer program lab and language course, and favorable, but informal, evaluations by French CPE faculty and participating US 
NCSU students. The second report (2), written by the US faculty recruiter and the French CPE program administrator, summarized an extensively revised offering of six weeks (now reduced to five), now providing seven total academic credits (4 for lab, 3 in language) fully transferable to the US home institution.

These two faculty ASEE reports are here extended here to provide perspective from Alex Kim, a NCSU student participant of the summer 2016 IPL program.

Prior programs: Context for the IPL CPE summer program.

A non-inclusive review of recent ASEE and other engineering education papers (3-9) describing international opportunities for engineering students appears below in Table 1. While program lengths and languages vary, these other opportunities annually require US faculty and salary time for the duration of the program overseas, with many described as "faculty-led" experiences. Such programs routinely suffer the challenge of raising faculty salary funding, and also involve higher program costs to the students. The same is true at our home institution ,NCSU.

The cost for the current five week summer program in IPL, France, is 2,000 Euro, or about $\$ 2,140$ US, and includes five weeks of accommodation, all visits and social events, and public transportation. For comparison, the cost for another study abroad program at a French four week summer abroad program for STEM students in Lille Catholic University is $\$ 6,250$, with technical instruction taught in English. 
Table 1

Example study abroad programs for US engineering students

\begin{tabular}{lll}
\hline US Institution & Program length & US faculty-led? \\
\hline Lincoln U. (3) & semester & Yes \\
Purdue U. (4) & one week & Yes \\
Robert Morris U. (5) & semester & Yes \\
U. Missouri (6) & month & Yes \\
U. Rhode Island (7) & five years & Yes \\
U. Rhode Island (7) & month (January) & Yes \\
Grove City College (8) & year & Yes \\
Stevens Institute of Technology (9) & two weeks & Yes \\
IPL-CPE Lyon (1,2) & five weeks & NO \\
& & \\
\hline
\end{tabular}

The French IPL program (Table 2)

The program shown above provides an integrated mix of formal language and scientific courses (labs) as well as visit to cities (Lyon, Annecy, Perouges, and Geneva), farms (vineyards), production sites ( food packaging, cheese making, and a chocolate factory) and manufacturing (Mavic/Salamon, Entremont) and research lab (CERN, Geneva). In addition to 
the formal 2016 schedule appearing in Table 2, students also had adequate weekend and evening time to explore the French culture of Lyon (museums, commerce, architecture, food, music, etc) Table 2

IPL program (all schools) (10) June 8-July 13, 2017

\begin{tabular}{|c|c|c|}
\hline Date & Morning & Afternoon \\
\hline June 8 & Arrival in Lyon & Dinner buffet at residence \\
\hline June 9 & Program presentation & Intercultural session \\
\hline June 12 & Scientific courses & Language \\
\hline June 13 & French: Farmer's market & French: Visit of Lyon \\
\hline June 14 & Tour: Chocolate city & Tour: Vineyards \\
\hline June 15 & Scientific courses & Scientific courses \\
\hline June 16 & Scientific courses & Language \\
\hline June 19 & Scientific courses & Language \\
\hline June 20 & Language & Language \\
\hline June 21 & Scientific courses & Language \\
\hline June 22 & Tour: Cheese factory & Culture: Tour Annecy \\
\hline June 23 & Tour: Mavic/Salomon factory & Tour: Entremont(foods) \\
\hline June 26 & Tour: Perouges (medieval city) & Tour: Perouges \\
\hline June 28 & Scientific courses & Scientific courses \\
\hline June 29 & Tour: Cheese producer & Language \\
\hline June 30 & Scientific courses & Scientific courses \\
\hline July 3,4 & Language & Language \\
\hline July 5 & Scientific courses & Scientific courses \\
\hline July 6 & Scientific courses & Language \\
\hline July 7 & Tour: Geneva & Tour: CERN, Geneva \\
\hline July 10 & Language & Language \\
\hline July 11 & Language & Evaluation; dinner \\
\hline Jully 12 & Inventory residences & Departures \\
\hline July 13 & Departures & \\
\hline
\end{tabular}

To analyze the differences in engineering educational style between the United States and France from a student's perspective, US participant Alex Kim observed and compared his 
home course experiences with those abroad. He paired this with a professional perspective by interviewing IPL faculty and asking them questions written prior to beginning the summer 2016 study abroad program.

To better understand the backgrounds and mindsets of the IPL student participants, he also conducted interviews with summer 2016 participants from a variety of backgrounds, including the United States, other European nations, and other non-American or European nations. (Table 3)

Table 3: List of Countries Represented in the IPL Student Body in 2010-2016 [10]

\begin{tabular}{|c|c|}
\hline Year & Countries Represented in Student Body \\
\hline 2010 & Germany, Iran, Japan, Mexico, Tunisia, UK, USA \\
\hline 2011 & Argentina, Japan, Mexico, Tunisia, USA \\
\hline 2012 & Argentina, Egypt, India, Japan, Mexico, Norway, Tunisia, USA \\
\hline 2013 & Egypt, India, Ireland, Mexico, Nigeria, Tunisia, USA \\
\hline 2014 & Canada, Chile, Denmark, Mexico, Thailand, Tunisia, USA, Venezuela \\
\hline 2015 & India, Mexico, Myanmar, Spain, Tunisia, USA \\
\hline 2016 & Canada, Germany, India, Italy, Japan, Jordan, Spain, USA \\
\hline
\end{tabular}

\section{Discussion}

Differences in Chemical Engineering Educational Style

The French "scientific course" (Table 2) offered at CPE-Lyon was a laboratory-based applied chemistry class which nicely replaced the first of a two-part series of required US chemical engineering lab courses. Laboratory experiments performed included distillation using 
a two-story tall column, mixing and stirring, pressure drop in pipes, chemical reactions, and several more. All associated theory was taught in a brief classroom setting one hour prior to performing each experiment, and data collected was analyzed in-class during and immediately after the experiment while guided by a French professor. The analyses were completed using Microsoft Excel or other specialized computer programs. The analysis was also conducted orally in fast-paced question-and-answer sessions, with targeted questions asked by the instructor to lead the students to a correct interpretation of the theory behind their lab observations. Each lab session, lasting several hours, was taught by a different professor, and thus students could access the collective breadth of CPE faculty technical experience throughout the course. In total, there were nine laboratory sessions across the five weeks, for a total of 40 hours of class time (Table 2).

This French laboratory structure is certainly different from the way an equivalent lab course is taught at the US home institution, where the brunt of theoretical understanding is presented in earlier coursework, and specific material that the US professor wishes the student to be aware of prior to performing the experiment is delivered in written form, to be read at home before coming to the lab. In many US campuses, the analyses and deep discussions are not performed with the professor present in the lab to guide the students, but rather students work in groups to analyze data and then provide formal written reports (30-60 pages) and presentations. Further, at home, approximately 28 hours are allotted in our total NCSU undergraduate curriculum for hands-on experience in the CHE-specific labs, substantially fewer than the 40 hours allotted for a single summer course at CPE-Lyon.

Before traveling to France, Alex Kim heard rumors that French engineering students were more advanced than their American peers, and he was interested in discovering whether or not 
this was true, or whether there was rather a difference in emphasized skills. He interviewed several CPE French professors. In an interview, the Assistant to the Chemistry and Chemical Engineering Scientific Direction at IPL stated that she and her faculty "...do not perceive the American students to be at a lower level than the French students." Other French professors, such as Dr. Peiere Monkham and Dr. Muriel de Montigny, remarked that they believed the same. They noticed that on the whole, however, the American students did not have the same practical (i.e. in-lab) experience that French students would have by the same point in their academic careers, and that American engineering education tended to be more theoretical. At $\mathrm{CPE}$ in France, hands-on chemical engineering instruction begins in the first year of engineering education, whereas at his US home institution, lab instruction typically does not begin until the second semester of the third year of the four-year undergraduate plan.

In addition, CPE practical lab experience related to the lecture-based class is incorporated into each core French chemical engineering class, from transport phenomena and separation processes to chemical kinetics and reactors. At US NCSU, on the other hand, these core classes include no practical component; instead, all practical experience is received later in two exclusively lab-based junior/senior courses.

With plenty of hands-on instruction and analysis guided by a professor, he found performing the nine different experiments to be exciting. The physical nature of experimentation reinvigorated his love for engineering, and he wished he had more formalized access to such hands-on activities at NCSU. In high school, he assumed that the path to becoming a proficient engineer and problem solver in engineering school would be accomplished primarily through practical experience. This assumption did not turn out to be the case. As discussed earlier, the typical US chemical engineering student at NCSU does not encounter an engineering lab course 
until the last third of their academic career, and consequently, prior chemical engineering coursework is purely theoretical and idealized. Exorbitant amounts of time are spent independently writing lab reports, and relatively little is spent on hands-on instruction as compared to what is experienced by French engineering CPE students. If he were had been exposed to the exciting, physical nature of chemical engineering from the first days of his career, he would have been undoubtedly more inspired and motivated to complete other technical coursework as well by having seen the physical manifestation of the subjects studied in class. After experiencing IPL's CPE focus on practical instruction first-hand, and the subsequent excitement raised in him and the other summer students, he strongly suggests that American chemical engineering students should seek out this kind of early, practical laboratory experience to broaden their academic experience and passion for the subject material. Further, they should also encourage their home engineering departments and engineering schools to incorporate more hands-on engineering learning into their core engineering classes.

Improved Language Skills and Understanding of Foreign Culture

In addition to experiencing a scientific lab course, IPL required that each summer student take a French language course. On arrival at IPL, each international summer student was evaluated for their French proficiency, and subsequently placed into a beginner, intermediate, or advanced-level language course. Importantly, all levels, including the beginner class, did not employ the use of English to facilitate instruction through translation. This language immersion approach certainly contrasts with most beginner foreign language instruction in the United States, where copious amounts of English are commonly employed. Two fellow American NCSU students were placed into the beginner class, and it was impressive to watch their 
dramatic language improvement as a result of this total immersion in French, both inside and outside of class. The benefits extended beyond simply learning French, however. As a result of the impact of the intense French courses, one student was inspired to begin taking Spanish classes again when he returned to the United States.

For the advanced language course in which he participated, the instruction focused less on conjugations and formal French, but rather prioritized on refinement, conversation, and understanding of idiomatic expressions to truly sound like a French native. This approach paralleled his experience in the scientific courses IPL offered - rather than focusing on the theoretical or idealized usage of concepts, the course emphasized the understanding of real-life, practical situations. To him and his peers, this form of language instruction was a considerable benefit, as he was able to achieve a much higher level of French fluency by learning language nuances that would be difficult to obtain in a US classroom, due to the lack of cultural and linguistic immersion also taking place outside of class.

To deepen this immersion, IPL ensured that participants took many outings and field trips to experience French culture at large. Trips to CERN in nearby Geneva, a French vineyard, local museums such as the Musée des Confluences, a cheese producer in the French Alps, and a Mavic/Saloman R\&D and manufacturing center were all parts of the program(Table 2). These external visits provided a well-rounded experience that was both scientifically informative as well as culturally horizon-broadening. Visiting Mavic was an especially valuable experience for him, as the manufacturing environment looked similar to what he had experienced when working in plants in the United States. This realization bolstered his confidence that he could one day take an engineering job in France, or another country, and be comfortable in that environment. 
Another remarkable experience IPL offered to facilitate cultural immersion was scheduling a dinner for each student in a faculty member's home. This event provided an opportunity to engage in hours of French conversation, make new friends, taste some homemade French foods, and learn French dining customs in the home. For example, during the dinner he attended, he met two of the host faculty's family members who were both nuclear engineers. When he thinks back to his time in Lyon, this dinner stands out as one of the highlights.

Though IPL is only five weeks long, it was packed with presentation, conversation, and cultural immersion opportunities. As an engineer or academic, being able to speak a second language proficiently is valuable, and may open many doors. The opportunity to vastly improve his language skills in such a short time was a very worthwhile investment, and is highly recommended for an engineering student seeking a career in an increasingly globalized world.

Make connections with people from all around the world

One of the most important benefits of studying abroad, and often the singular reason that students seek out opportunities to do so, is the ability to immerse one's self in the foreign culture and language outside of class. IPL takes this one step further with a unique benefit that is not present in many competing study abroad programs - the student body of IPL is not solely American, but is instead international. From 2010-2016, attendees came from a wide range of countries, as can be seen in Table 3[10].

These non-US students did not come in small numbers, as Americans were in the minority in nearly every year from 2010-2016 as can be seen in Table 4 below. 
Table 4: IPL Student Body Size and Percent of American Students [10]

\begin{tabular}{|c|c|c|}
\hline Year & $\begin{array}{c}\text { Size of Student Body } \\
\text { (\# of people) }\end{array}$ & $\begin{array}{c}\text { Percent of Student Body } \\
\text { Comprised of Americans (\%) }\end{array}$ \\
\hline 2010 & 16 & $37.5 \%$ \\
\hline 2011 & 25 & $56 \%$ \\
\hline 2012 & 26 & $23 \%$ \\
\hline 2013 & 27 & $34.4 \%$ \\
\hline 2014 & 39 & $25 \%$ \\
\hline 2015 & 28 & $48 \%$ \\
\hline 2016 & 25 & \\
\hline
\end{tabular}

Interestingly, the closest friends that he made while abroad were not French, but Spanish. These new friends and his fellow NCSU students, traveled together with him on weekend trips and learned about each other's cultures and backgrounds while making new memories. One of the most remarkable lessons he learned was that despite different cultural backgrounds, and likely because of the prevalence of Internet usage among millennials, they all understood the same references to pop culture, listened to similar or identical music, and laughed at the same Internet-wide jokes. He has stayed in touch with many of these friends, and half a year later, still communicates with some on daily basis.

In his French class, he had classmates from Jordan and Japan, and in the chemical engineering lab course, he was working in a lab group with students from Mexico and India. 
Experiencing work and communication in a scientific context with non-American engineering student was another enlightening experience, certainly beneficial for a global career. For instance, he learned from an Indian student how their engineering schools place enormous emphasis on performing mathematical analysis and computations manually by pencil-and-paper. Thus, when it came time to analyze lab data from an experiment, his first reaction was to open Microsoft Excel, whereas his Indian counterpart was to reach for a notepad.

He has spoken with other NCSU friends who have participated in other US universitysponsored study abroad programs, and one of their chief complaints was that they didn't always feel as if they were studying abroad or being immersed in the foreign culture to the degree that they expected. In many of these other programs, students travelled with a group of US friends or peers exclusively from NCSU or other American institutions, and their classes abroad were wholly comprised of other Americans. Thus, during all their free time outside of class, they would remain with each other and speak English. In a program like IPL, where the student body is international, the likelihood of this self-imposed cultural isolation occurring is reduced as both class and free time require interactions with non-Americans and non-English speakers.

The main benefit he was seeking - to improve his French and further his engineering education — was not always the same benefit others most highly prioritized. For instance, one Italian student remarked that she signed up for IPL to practice her English among all the other attendees who held a grasp of English in common. A Spanish student had a similar reason, and controversially remarked that he'd be "OK if all languages except English were made to be illegal, because then we'd all be able to communicate." For both of these students, studying abroad was solely meant to increase their chances of being able to communicate effectively with as many people as possible, which was of paramount importance to them as an engineer in an 
increasingly globalized world. This viewpoint should be of similar importance to American students as well.

Surprise opportunity

Near the end of the IPL summer visit, the French faculty CPE interviewed him for a promotional VIDEO contribution for their university program. A video of his exciting opportunity is found at the following web address:

https://www.youtube.com/watch?v=dlHeeUT4-hk It provides first-hand evidence of the power of a language immersion experience.

\section{Conclusions}

By studying abroad, as well as through the interviews and conversations outlined herein, he and his fellow American engineering students were able to see how engineering education is conducted and prioritized differently in another country, France. By being inspired and excited by hands-on instruction, and realizing that this is one area in which American universities could improve, we can recommend changes for departments and engineering college administrations to consider to strengthen US programs at home. Should he ever become a teacher, he will incorporate more hands-on learning into his classes. In addition, because IPL's program structure ensures interactions with international students from different countries, he has an improved understanding of how to interact and relate with people from substantially different backgrounds. As most large firms have global operations nowadays (as do research universities), having this kind of cultural understanding is an invaluable asset. In addition, this program has inspired him and other students to further their language education, which will, in turn, open doors and 
increase the number of people they can interact and collaborate with over the course of their careers. The IPL experience was powerful based on its structure such that these benefits and lessons were realized in a short and affordable five weeks, and thus we highly recommend that American engineering students seek out this or similar opportunities and have such experiences prior to their graduation.

\section{References}

(1) A. Wilson and D Ollis, A Summer Immersion in French Engineering and Language, ASEE 2001 Annual Conference Proceedings.

(2) D. Ollis and A. Smith, Summer On-Site Immersion in French Language and Engineering, ASEE 2008 Annual Conference Proceedings.

(3) M. Gray and C. Lundy, First Learning, then Lifelong Learning: Engineering Study Abroad to Increase Access and Retention among Minorities and Under-Represented Groups, ASEE International Forum, Seattle, WA, June, 2015.

(4) H.W. Kraebber, E.S. Donaldson, and K. M. Hackney, Impact of Study Abroad - 10 Years of Trips to Germany with Students, ASEE International Forum, Indianapolis, IN, June, 2014.

(5) S. Acharya, L. Nutt, and T. Kersmann, Development of a Faculty-Led Education Abroad Program and the Lessons Learned, ASEE Annual Conference Proceedings, 2014.

(6) R. O’Connell and M. Ayllon, Student Perceptions of Global Knowledge and Skills Acquird During a Five-Week Study Abroad Program, IEEE 2016. 
(7) S. Berka, E. A. Serman, M. Echeverria, L. Erickson, S.Scholz, and A. Geithner, Integrating a Portfolio of Short with Long-term International Programs in the Engineering Curriculum, ASEE International Forum, Seattle, WA, June, 2016.

(8) E. Bardly and M. Reuber, Instrumentation Laboratory at a Foreign Study Center with Concurrent Instructions, Interdisciplinary Engineering Design Education Conference, IEEE, 2013.

(9) K. Abel and E. Specking, Why Did the EM(Engineering Management Study Abroad Program Become one of the Most Popular on Campus?, ASEE Annual Conference Proceedings, Indianapolis, 2014..

(10) Beaucourt, Maria-Angelina, CPE-Lyon, France (2016). Demographic Survey of 2010 2016 IPL Participants. 